\title{
Efficacy of a microencapsulated iron pyrophosphate-fortified fruit juice: a randomised, double-blind, placebo-controlled study in Spanish iron-deficient women
}

\author{
Ruth Blanco-Rojo ${ }^{1}$, Ana M. Pérez-Granados ${ }^{1}$, Laura Toxqui ${ }^{1}$, Carmen González-Vizcayno ${ }^{2}$, \\ Marco A. Delgado ${ }^{3}$ and M. Pilar Vaquero ${ }^{1 *}$ \\ ${ }^{1}$ Department of Metabolism and Nutrition, Institute of Food Science and Technology and Nutrition (ICTAN), \\ Spanish National Research Council (CSIC), C/José Antonio Novais 10, 28040 Madrid, Spain \\ ${ }^{2}$ Clinical Analysis Laboratory, Madrid Salud, Madrid, Spain \\ ${ }^{3}$ Grupo Leche Pascual, Aranda de Duero, Burgos, Spain
}

(Received 12 July 2010 - Revised 29 November 2010 - Accepted 30 November 2010 - First published online 8 February 2011)

\begin{abstract}
Fe-deficiency anaemia is a worldwide health problem. We studied the influence of consuming an Fe-fortified fruit juice on Fe status in menstruating women. A randomised, double-blind, placebo-controlled study of 16 weeks of duration was performed. Subjects were randomised into two groups: the P group ( $n$ 58) or the F group ( $n$ 64), and consumed, as a supplement to their usual diet, $500 \mathrm{ml} / \mathrm{d}$ of a placebo fruit juice or an Fe-fortified fruit juice, respectively. The Fe-fortified fruit juice, containing microencapsulated iron pyrophosphate, provided $18 \mathrm{mg} \mathrm{Fe} / \mathrm{d}(100 \%$ of the RDA). At baseline and monthly, dietary intake, body weight and Fe parameters were determined: total erythrocytes, haematocrit, mean corpuscular volume (MCV), red blood cell distribution width (RDW), Hb, serum Fe, serum ferritin, serum transferrin, transferrin saturation, soluble transferrin receptor (sTfR) and zinc protoporphyrin (ZnPP). The fruit juice consumption involved increased intake of carbohydrates and vitamin $\mathrm{C}$, and increased BMI within normal limits. Ferritin was higher in the F group after week 4 $(P<0.05)$ and became $80 \%$ higher than in the $\mathrm{P}$ group after week $16(P<0.001)$, and transferrin decreased in the $\mathrm{F}$ group compared with the $\mathrm{P}$ group after week $4(P<0 \cdot 001)$. RDW was higher at weeks 4 and 8 in the $\mathrm{F}$ group compared with the $\mathrm{P}$ group $(P<0 \cdot 05)$. Transferrin saturation increased after week 8 , and haematocrit, MCV and $\mathrm{Hb}$ increased after week 12 , in the F group compared with the P group. Serum Fe did not change. sTfR and ZnPP decreased in the F group at week $16(P<0.05)$. Iron pyrophosphate-fortified fruit juice improves Fe status and may be used to prevent Fe-deficiency anaemia.
\end{abstract}

Key words: Fortification: Ferric pyrophosphate: Iron-deficiency anaemia: Iron status: Women

Nutritional Fe deficiency has been identified as one of the ten leading factors for disease, disability and death in the world today. An estimated two billion people are affected, and the population at risk includes women of child-bearing age and children. It is the only highly frequent nutritional deficiency in developing and developed countries ${ }^{(1)}$.

Dietary strategies for combating Fe deficiency include Fe supplementation, dietary modification and diversification, and food fortification ${ }^{(2)}$. Our research group has recently observed in young women that the current RDA of $18 \mathrm{mg}$ $\mathrm{Fe} / \mathrm{d}^{(3,4)}$ was not easily reached, even though the volunteers consumed five portions of red meat and two portions of poultry per week ${ }^{(5)}$. Supplementation with doses of $\mathrm{Fe} \geq 100 \mathrm{mg} / \mathrm{d}$ is efficacious to increase Fe status, but its major limitation is low compliance due to gastrointestinal discomfort ${ }^{(2)}$. Finally, fortification is widely considered to be the most practical and cost-effective prevention programme ${ }^{(6)}$. However, Fe is the most challenging micronutrient to add to foods, because the Fe compounds that have the best bioavailability tend to be those that interact most strongly with food constituents producing undesirable organoleptic changes ${ }^{(7)}$. Among $\mathrm{Fe}$ fortificants, ferric pyrophosphate allows appropriate food processing, and it is easily and effectively absorbed while producing negligible colour and palatability changes ${ }^{(8-10)}$.

It is well known that the food matrix strongly affects $\mathrm{Fe}$ bioavailability ${ }^{(11)}$. Therefore, in addition to the Fe salt, the effectiveness of consuming Fe fortificants is highly dependent on the type of food used.

Abbreviations: AA, ascorbic acid; F, fortified group; P, placebo group; RDW, red blood cell distribution width; STfR, soluble transferrin receptor; ZnPP, zinc protoporphyrin

*Corresponding author: M. P. Vaquero, fax +34 915943627, email mpvaquero@ictan.csic.es 
Ascorbic acid (AA) is the most important enhancer of Fe absorption, both for its ability to improve Fe absorption in the lumen and for overcoming the negative effect of inhibitors $^{(12-14)}$. However, there are doubts concerning the applicability of single-meal results to the practical diet.

Cook \& Reddy ${ }^{(15)}$ studied Fe absorption from three diets varying in AA and concluded that the effect of vitamin $\mathrm{C}$ on Fe absorption from a complete diet was far less pronounced than that from single meals. A better Fe status is reached when AA is consumed with meals containing substantial amounts of added $\mathrm{Fe}^{(10,13)}$.

Nevertheless, studies that used foods with a naturally high content of AA are scarce ${ }^{(16)}$. Fruit juices can contain high quantities of vitamin $\mathrm{C}$, low $\mathrm{pH}$ and no Fe absorption inhibitors, and should be considered as target products to fortify with Fe.

An orange juice fortified with iron sulphate $(2 \mathrm{mg} \mathrm{Fe} / 100 \mathrm{ml})$ given to Brazilian preschool children during 4 months (mean Fe intake $5.7 \mathrm{mg} / \mathrm{d}$ ) increased $\mathrm{Hb}$ levels and decreased the percentage of anaemic children from 60 to $20 \%{ }^{(16)}$. Other studies have been performed using multiple-micronutrient-fortified powdered beverages containing iron bis-glycinate. These beverages reduced the overall prevalence of anaemia in children, adolescent girls and pregnant women of developing countries ${ }^{(17-21)}$.

The present study therefore aims to investigate the influence of the consumption, as a part of the usual diet, of an Fefortified fruit juice on $\mathrm{Fe}$ metabolism in young Spanish Fe-deficient women.

This trial was registered at clinicaltrials.gov as NCT0 1135576.

\section{Subjects and methods}

The present study was designed and carried out following the statement guidelines of the Consolidated Standards of Reporting Trials ${ }^{(22)}$.

\section{Subjects}

Volunteers were recruited by different announcements in the press, university campus and web pages of Madrid. The study was also verbally promoted at public events.

The principal variable for the calculation of sample size was ferritin, with a mean value for the deficient population of 11 (SD 5) ng/ml. It was calculated that a minimum of sixty-three subjects with low Fe stores would be required in each group to demonstrate a difference of 2.5 units in serum ferritin between two treatments at $80 \%$ power and confidence level at $95 \%$.

Women aged 18-35 years, non-smoker, non-pregnant, nonbreast-feeding, with low Fe stores, defined as serum ferritin $<40 \mathrm{ng} / \mathrm{ml}$ and $\mathrm{Hb} \geq 110 \mathrm{~g} / 1$, were included in the present study. The cut-off value for serum ferritin was selected because a normal or elevated ferritin value does not exclude the presence of Fe deficiency, and cut-off ranges between 25 and $50 \mathrm{ng} / \mathrm{ml}$ are usually considered in studies dealing with predisposition to anaemia ${ }^{(5,23)}$. Subjects were excluded from the study if they had amenorrhoea, menopause or any known health problems likely to influence Fe status including Fe metabolism-related diseases (Fe-deficiency anaemia, thalassaemia and haemochromatosis), chronic gastric diseases (inflammatory bowel disease, Crohn's disease, gastric ulcers, coeliac disease and haemorrhagic diseases), renal disease or allergy to any of the components of the assay juices. Other exclusion criteria were blood donors or to have regularly consumed Fe or AA supplements within the 4 months before participating in the intervention.

A group of 259 women contacted the research group in order to participate in the study, but only 163 underwent screening. Out of the 163 women, thirty-three were excluded (twenty-eight did not meet the inclusion criteria and five refused to participate). Finally, a total of 130 women agreed to participate in the nutritional intervention. They were randomised into two groups: fortified (F) and placebo (P). All volunteers of the F group completed the assay while eight participants of the P group abandoned the intervention (Fig. 1).

Participating women were instructed not to deviate from their regular habits and to maintain their normal diet and exercise level during the 4 months.

The present study was conducted according to the guidelines laid down in the Declaration of Helsinki, and all procedures involving human subjects/patients were approved by the Clinical Research Ethics Committee of Hospital Puerta de Hierro, Madrid. Written informed consent was obtained from all subjects.

\section{Study design}

The study consisted of a randomised double-blind study controlled by placebo of 16 weeks' duration.

The volunteers recruited were randomly allocated into two groups, using the RAND function in Excel (Microsoft Office 2003). One group consumed, as a supplement to their usual diet, $500 \mathrm{ml} / \mathrm{d}$ of the Fe-fortified fruit juice (F group, $n$ 64), whereas the other consumed $500 \mathrm{ml} / \mathrm{d}$ of the placebo fruit juice (P group, $n$ 66). Fortified and placebo juices were manufactured in $500 \mathrm{ml}$ cartons and in two different tastes (orange and peach apple) to achieve compliance. The fortified juice supplied $18 \mathrm{mg} \mathrm{Fe} / 500 \mathrm{ml}$ carton, in the form of microencapsulated iron pyrophosphate coated with lecithin, equivalent to $100 \%$ of the $\mathrm{RDA} / \mathrm{d}^{(3,4)}$. All juices were fortified with vitamin C. Nutritional composition of the juices was facilitated by the manufacturer (Grupo Leche Pascual, Burgos, Spain). Orange juices provided (per $100 \mathrm{ml}$ ) $188 \mathrm{~kJ}, 0.6 \mathrm{~g}$ of protein, $10.5 \mathrm{~g}$ of carbohydrate and $19 \mathrm{mg}$ of vitamin C; the Fe-fortified orange juice provided $3.6 \mathrm{mg}$ of $\mathrm{Fe}$, whereas the placebo juice had $0.084 \mathrm{mg}$. Peach apple juices provided (per $100 \mathrm{ml}) 201 \mathrm{~kJ}$, $0.6 \mathrm{~g}$ of protein, $11.3 \mathrm{~g}$ of carbohydrate and $19 \mathrm{mg}$ of vitamin $\mathrm{C}$; the Fe-fortified peach apple juice provided $3.6 \mathrm{mg}$ of $\mathrm{Fe}$, whereas the placebo juice had $0 \cdot 136 \mathrm{mg}$.

Participants were instructed to alternate between juice flavours (orange juice one day, peach apple juice the next day). The $500 \mathrm{ml}$ carton had to be drunk all at once separately from meals (by at least $2 \mathrm{~h}$ ) and shaken before consumption. 


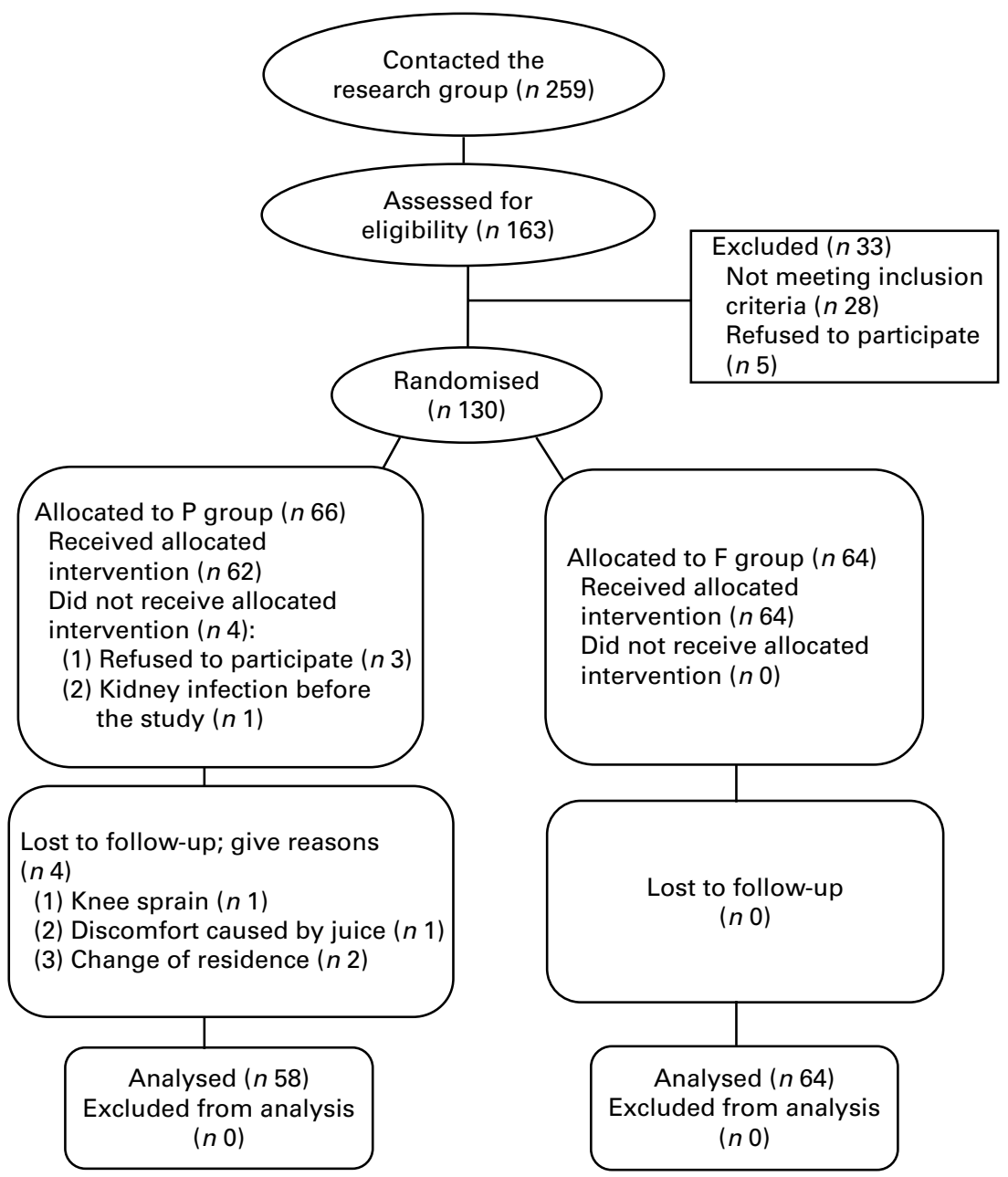

Fig. 1. Diagram of the Consolidated Standards of Reporting Trials.

Volunteers who could not drink the juice one day were instructed to consume two juice cartons the following day.

\section{Dietary control and compliance}

Each subject's dietary intake was evaluated at baseline and monthly to control any possible changes in energy and nutrient intakes. They completed a $72 \mathrm{~h}$ detailed dietary intake report, previously validated and proved valuable to assess nutrient intake ${ }^{(24,25)}$, specifying the types of food consumed and serving weights. Daily food, energy intake, nutrient intake and energy provided by macronutrients were calculated by a computer application using the Spanish Food Composition Database ${ }^{(26)}$. The compliance of the study was assessed monthly by questionnaires and personal interview when volunteers underwent blood sampling.

\section{Anthropometric, blood pressure and physical activity determinations}

Once a month, anthropometric measures were taken using standardised procedures. Body weight was measured with a calibrated Seca scale (to a precision of $100 \mathrm{~g}$ ), and height was measured at baseline with a stadiometer incorporated into the scale. Duplicate waist circumference was taken to the nearest $0 \cdot 1 \mathrm{~cm}$ using an inelastic, flexible tape measure. BMI was calculated as weight/height squared $\left(\mathrm{kg} / \mathrm{m}^{2}\right)$. To avoid inter-examiner variability, one trained member of the research team did all anthropometric determinations. International manual procedures were used ${ }^{(27)}$.

Physical activity was assessed by a validated questionnaire after weeks 4 and 12. This questionnaire was completed during face-to-face interviews conducted by a trained dietitian. Women were asked about their occupation, sleeping hours and additional activities at work and during the rest of the day. The physical activity questionnaire included representative values expressed as multiples of resting energy expenditure. Average daily exercise was calculated taking into account the intensity level and time spent on each activity. Activities were divided into five categories and expressed as an activity factor (resting $=1$, very light $=1 \cdot 5$, light $=2 \cdot 5$, moderate $=5$ and heavy $=7)^{(28)}$.

In addition, every 4 weeks, women completed a questionnaire about physical discomfort or health problems, medication use and changes in their normal routine. 


\section{Blood sampling and biochemical assays}

Volunteers attended the laboratory facilities at baseline, 4, 8, 12 and 16 weeks. Blood samples were collected by venepuncture after a $12 \mathrm{~h}$ fasting period. Serum and plasma were obtained after centrifugation at $1000 \mathrm{~g}$ for $15 \mathrm{~min}$ and stored at $-80^{\circ} \mathrm{C}$.

Total erythrocytes, haematocrit, mean corpuscular volume, red blood cell distribution width (RDW) and Hb were determined following standard laboratory techniques using the Symex NE 9100 automated haematology analyser (Symex, Kobe, Japan). Serum Fe, serum ferritin and serum transferrin were determined by the Modular Analytics Serum Work Area analyser (Roche, Basel, Switzerland). Total iron-binding capacity (TIBC) and transferrin saturation were calculated as follows:

$$
\operatorname{TIBC}(\mu \mathrm{mol} / \mathrm{l})=25 \cdot 1 \times \operatorname{transferrin}(\mathrm{g} / \mathrm{l}),
$$

Transferrin saturation $=\operatorname{serum~Fe}(\mu \mathrm{mol} / 1) / \operatorname{TIBC} \times 100$.

Serum soluble transferrin receptor (sTfR) concentration was determined using an ELISA technique (sTfR Human ELISA; Biovendor, Heidelberg, Germany) and erythrocyte zinc protoporphyrin (ZnPP) by haematofluorophotometry (haematofluorophotometer AVIV 206; Izasa, Barcelona, Spain). Values of $\mathrm{ZnPP} \mu \mathrm{g} / \mu \mathrm{g} \mathrm{Hb}$ were converted to $\mu \mathrm{mol} / \mathrm{mol}$ haem of erythrocyte protoporphyrin by using a factor of $25 \cdot 76$.

All determinations were subjected to the ISO 9001-2000 requirements, except for the transferrin receptor; the intraassay $\mathrm{CV}$ of this determination was $3.5 \%$ and the inter-assay CV was $4.3 \%$.

\section{Statistical analysis}

Data are presented as means and standard deviations. A normal distribution of variables was determined by the Kolmogorov-Smirnov test. Serum ferritin values were log-transformed for statistical testing. A two-way repeatedmeasures ANOVA was applied. Because a significant group $\times$ time interaction was found for the main variables (ferritin, transferrin and $\mathrm{Hb}, P \leq 0 \cdot 001$ ), the repeated-measures ANOVA and the Bonferroni post hoc test were used to study the time effect within groups. Comparisons were also made between the $\mathrm{F}$ group and the $\mathrm{P}$ group using ANOVA. A $P$ value of $<0.05$ was considered significant. Data were analysed using the SPSS statistical package for Windows (version 17.0; SPSS Inc., Chicago, IL, USA).

\section{Results}

A total of 122 volunteers completed the study (Fig. 1). Ages of the volunteers were 24.5 (SD 5.1) and $24 \cdot 2$ (SD 4.6) years for the $\mathrm{P}$ and $\mathrm{F}$ groups, respectively. Energy and nutrient intakes at baseline and week 16 are shown in Table 1.

No significant differences between groups were found in the baseline characteristics of subjects (Tables 2 and 3). Compliance rate was confirmed to be very high (approximately $100 \%$ ).
Table 1. Energy and macronutrient intakes of iron-deficient women consuming placebo and iron-fortified fruit juices during 16 weeks (Mean values and standard deviations)

\begin{tabular}{|c|c|c|c|c|c|}
\hline \multirow[b]{2}{*}{ Groups } & \multicolumn{2}{|c|}{ Baseline } & \multicolumn{2}{|c|}{ Week 16} & \multirow[b]{2}{*}{ Time effect $(P) \dagger$} \\
\hline & Mean & SD & Mean & SD & \\
\hline \multicolumn{6}{|l|}{ Energy (kJ) } \\
\hline Placebo & 9452 & 2179 & 9826 & 2493 & NS \\
\hline Fortified & 8807 & 2108 & 9285 & 2292 & NS \\
\hline \multicolumn{6}{|c|}{ Protein (\% energy) } \\
\hline Placebo & $15 \cdot 2$ & 3.9 & $13 \cdot 0$ & $2 \cdot 4$ & $<0.001$ \\
\hline Fortified & $14 \cdot 6$ & $2 \cdot 4$ & $13 \cdot 6$ & $2 \cdot 3$ & 0.004 \\
\hline \multicolumn{6}{|c|}{ Carbohydrate (\% energy) } \\
\hline Placebo & $41 \cdot 2$ & $7 \cdot 3$ & $45 \cdot 0$ & $7 \cdot 3$ & 0.001 \\
\hline Fortified & $41 \cdot 2$ & $6 \cdot 2$ & 44.6 & $6 \cdot 6$ & $<0.001$ \\
\hline \multicolumn{6}{|c|}{ Lipid (\% energy) } \\
\hline Placebo & 39.9 & $7 \cdot 8$ & $37 \cdot 3$ & $6 \cdot 3$ & NS \\
\hline Fortified & 39.7 & 6.5 & $36 \cdot 4$ & $6 \cdot 8$ & 0.001 \\
\hline \multicolumn{6}{|l|}{$\mathrm{Fe}(\mathrm{mg})$} \\
\hline Placebo & $15 \cdot 1$ & 4.7 & $12 \cdot 9$ & 4.7 & 0.001 \\
\hline Fortified & $13 \cdot 7^{*}$ & $5 \cdot 9$ & $30 \cdot 4^{\star \star \star}$ & 7.5 & $<0.001$ \\
\hline \multicolumn{6}{|c|}{ Vitamin C (mg) } \\
\hline Placebo & $145 \cdot 9$ & $60 \cdot 1$ & $199 \cdot 8$ & 64.9 & $<0.001$ \\
\hline Fortified & $118 \cdot 3$ & $59 \cdot 3$ & $190 \cdot 2$ & $66 \cdot 0$ & $<0.001$ \\
\hline
\end{tabular}

Mean values were significantly different from the placebo group at each point (measured using one-sided tests): ${ }^{\star} P<0.05,{ }^{\star \star \star} P<0.001$.

$\dagger$ Time-point differences were analysed by repeated-measures ANOVA.

Although energy intake did not show significant differences between baseline and week 16 in both groups, an increase between week 4 and baseline was observed to be significant in the $\mathrm{F}$ group $(9767 v .8807 \mathrm{~kJ} / \mathrm{d}$ for week 4 and baseline, respectively, $P<0 \cdot 05)$. A significant decrease in the energy percentage from proteins and an increase in that from carbohydrates were observed during the study in both groups, and a decrease in the energy percentage from lipids was observed only in the F group. The differences between the groups were not significant (Table 1).

At baseline, Fe intake was slightly lower in the $\mathrm{F}$ group compared with the $\mathrm{P}$ group, and due to the Fe-fortified juice consumption, it was about twice that of the $\mathrm{P}$ group for the duration of the intervention. In contrast, $\mathrm{Fe}$ intake of the $\mathrm{P}$ group decreased with time, and it was significantly lower at week 16 compared with baseline. Vitamin C intake increased

Table 2. Anthropometric values of iron-deficient women consuming placebo and iron-fortified fruit juices during 16 weeks

(Mean values and standard deviations)

\begin{tabular}{|c|c|c|c|c|c|}
\hline \multirow[b]{2}{*}{ Groups } & \multicolumn{2}{|c|}{ Baseline } & \multicolumn{2}{|c|}{ Week 16} & \multirow[b]{2}{*}{ Time effect $(P)^{\star}$} \\
\hline & Mean & SD & Mean & SD & \\
\hline \multicolumn{6}{|l|}{ Weight (kg) } \\
\hline Placebo & $57 \cdot 5$ & $6 \cdot 4$ & $58 \cdot 5$ & $6 \cdot 6$ & $<0.0001$ \\
\hline Fortified & $59 \cdot 6$ & $7 \cdot 6$ & $60 \cdot 5$ & $7 \cdot 8$ & $<0.0001$ \\
\hline \multicolumn{6}{|l|}{ BMI $\left(\mathrm{kg} / \mathrm{m}^{2}\right)$} \\
\hline Placebo & $21 \cdot 6$ & $2 \cdot 2$ & $22 \cdot 0$ & $2 \cdot 2$ & $<0.0001$ \\
\hline Fortified & $21 \cdot 8$ & $2 \cdot 3$ & $22 \cdot 1$ & 2.4 & $<0.0001$ \\
\hline \multicolumn{6}{|c|}{ Waist circumference $(\mathrm{cm})$} \\
\hline Placebo & 68.7 & $4 \cdot 7$ & $68 \cdot 8$ & $4 \cdot 6$ & NS \\
\hline Fortified & $69 \cdot 6$ & $5 \cdot 4$ & $69 \cdot 8$ & $5 \cdot 4$ & NS \\
\hline
\end{tabular}

Mean values were not significant between the placebo and fortified groups at each point.

* Time-point differences were analysed by repeated-measures ANOVA. 
Table 3. Haematological and biochemical markers of iron-deficient women consuming placebo and iron-fortified fruit juices during 16 weeks (Mean values and standard deviations)

\begin{tabular}{|c|c|c|c|c|c|c|c|c|c|c|c|}
\hline \multirow[b]{2}{*}{ Groups } & \multicolumn{2}{|c|}{ Baseline } & \multicolumn{2}{|c|}{ Week 4} & \multicolumn{2}{|c|}{ Week 8} & \multicolumn{2}{|c|}{ Week 12} & \multicolumn{2}{|c|}{ Week 16} & \multirow[b]{2}{*}{ Time effect $(P) \dagger$} \\
\hline & Mean & SD & Mean & SD & Mean & SD & Mean & SD & Mean & SD & \\
\hline \multicolumn{12}{|c|}{ Total erythrocytes $\left(\times 10^{-12} / \mathrm{l}\right)$} \\
\hline Placebo & 4.50 & 0.35 & 4.49 & 0.33 & 4.48 & 0.29 & 4.51 & 0.34 & 4.45 & 0.30 & NS \\
\hline Fortified & $4 \cdot 51^{a, b}$ & 0.30 & $4.49^{\mathrm{a}}$ & 0.32 & $4 \cdot 53^{\mathrm{a}, \mathrm{b}}$ & 0.32 & $4.56^{\mathrm{b}}$ & 0.31 & $4 \cdot 53^{\mathrm{a}, \mathrm{b}}$ & 0.30 & 0.046 \\
\hline \multicolumn{12}{|c|}{ Haematocrit (\%) } \\
\hline Placebo & $39 \cdot 3$ & $2 \cdot 9$ & $39 \cdot 2$ & $2 \cdot 8$ & 38.9 & 2.5 & 38.9 & $2 \cdot 6$ & $38 \cdot 7$ & $2 \cdot 6$ & NS \\
\hline Fortified & $39 \cdot 0^{\mathrm{a}}$ & $2 \cdot 8$ & $39 \cdot 4^{\mathrm{a}}$ & $2 \cdot 5$ & $39 \cdot 4^{a}$ & $2 \cdot 7$ & $40 \cdot 1^{b * *}$ & $2 \cdot 6$ & $39 \cdot 9^{a, b * *}$ & $2 \cdot 4$ & 0.006 \\
\hline \multicolumn{12}{|c|}{ Mean corpuscular volume (fl) } \\
\hline Placebo & $87 \cdot 4^{\mathrm{a}}$ & $4 \cdot 8$ & $87 \cdot 3^{\mathrm{a}}$ & $4 \cdot 3$ & $87 \cdot 0^{\mathrm{a}, \mathrm{b}}$ & $4 \cdot 3$ & $86 \cdot 5^{\mathrm{b}}$ & $4 \cdot 1$ & $87 \cdot 0^{\mathrm{a}, \mathrm{b}}$ & $4 \cdot 2$ & 0.011 \\
\hline Fortified & $86 \cdot 6^{\mathrm{a}}$ & $5 \cdot 1$ & $87 \cdot 9^{\mathrm{b}, \mathrm{c}}$ & 3.9 & $87 \cdot 1^{\mathrm{a}, \mathrm{b}}$ & $4 \cdot 2$ & $88 \cdot 1^{\mathrm{c} *}$ & 3.6 & $88 \cdot 1^{\mathrm{c}}$ & 4.0 & 0.001 \\
\hline \multicolumn{12}{|c|}{ Red blood cell distribution width (\%) } \\
\hline Placebo & $12 \cdot 7^{\mathrm{a}}$ & 0.8 & $12 \cdot 8^{a}$ & 0.9 & $12 \cdot 9^{a}$ & 0.9 & $12 \cdot 9^{a}$ & 0.9 & $12 \cdot 8^{a}$ & 0.8 & NS \\
\hline Fortified & $13 \cdot 0^{\mathrm{a}}$ & $1 \cdot 2$ & $13 \cdot 7^{\mathrm{b} * \star}$ & $2 \cdot 3$ & $13 \cdot 5^{\mathrm{b} *}$ & 1.9 & $13 \cdot 0^{a}$ & $1 \cdot 2$ & $12 \cdot 7^{\mathrm{a}}$ & 0.7 & 0.003 \\
\hline \multicolumn{12}{|l|}{$\mathrm{Hb}(\mathrm{g} / \mathrm{l})$} \\
\hline Placebo & 133 & 9 & 133 & 9 & 132 & 8 & 132 & 8 & 132 & 8 & NS \\
\hline Fortified & $132^{\mathrm{a}}$ & 9 & $133^{\mathrm{a}}$ & 8 & $135^{\mathrm{b}}$ & 9 & $136^{\mathrm{b} *}$ & 9 & $136^{b_{* *}}$ & 8 & $<0.0001$ \\
\hline \multicolumn{12}{|c|}{ Zinc protoporphyrin ( $\mu \mathrm{mol} / \mathrm{mol}$ haem) } \\
\hline Placebo & - & & $79 \cdot 3^{\mathrm{a}, \mathrm{b}}$ & $26 \cdot 9$ & $79 \cdot 9^{a, b}$ & $29 \cdot 4$ & $76 \cdot 1^{\mathrm{a}}$ & 32.5 & $86 \cdot 1^{\mathrm{b}}$ & 33.7 & 0.049 \\
\hline Fortified & - & & $76 \cdot 5^{\mathrm{a}}$ & $28 \cdot 6$ & $69 \cdot 7^{\mathrm{b}, \mathrm{c}_{*}}$ & $26 \cdot 1$ & $67 \cdot 1^{b}$ & $24 \cdot 1$ & $74 \cdot 6^{\mathrm{a}, \mathrm{c} *}$ & $19 \cdot 3$ & $<0.0001$ \\
\hline \multicolumn{12}{|c|}{ Serum Fe (mmol/l) } \\
\hline Placebo & $14 \cdot 0$ & $7 \cdot 1$ & $16 \cdot 4$ & $10 \cdot 0$ & $14 \cdot 4$ & $7 \cdot 8$ & $15 \cdot 0$ & 6.9 & $14 \cdot 2$ & $6 \cdot 5$ & NS \\
\hline Fortified & $15 \cdot 5$ & 6.5 & $14 \cdot 7$ & $7 \cdot 2$ & $15 \cdot 2$ & $6 \cdot 7$ & $15 \cdot 5$ & $5 \cdot 8$ & $16 \cdot 0$ & $8 \cdot 3$ & NS \\
\hline \multicolumn{12}{|c|}{ Serum ferritin (ng/ml) } \\
\hline Placebo & $26 \cdot 9$ & $17 \cdot 9$ & $25 \cdot 0$ & $17 \cdot 4$ & $24 \cdot 8$ & $17 \cdot 7$ & $23 \cdot 1$ & $16 \cdot 2$ & $22 \cdot 8$ & $14 \cdot 9$ & NS \\
\hline Fortified & $25 \cdot 4^{\mathrm{a}}$ & $16 \cdot 5$ & $30 \cdot 7^{\mathrm{b} *}$ & $13 \cdot 6$ & $34 \cdot 1^{\mathrm{b}, \mathrm{c} * *}$ & $14 \cdot 8$ & $37 \cdot 3^{\mathrm{c}, \mathrm{d} \star \star \star}$ & $16 \cdot 5$ & $40 \cdot 7^{\mathrm{d} \star \star \star}$ & $17 \cdot 7$ & $<0.0001$ \\
\hline \multicolumn{12}{|c|}{ Serum transferrin $(\mathrm{mg} / \mathrm{l})$} \\
\hline Placebo & $3213^{\mathrm{a}}$ & 676 & $3114^{\mathrm{b}}$ & 628 & $3208^{a, b}$ & 618 & $3104^{a, b}$ & 638 & $3232^{a, b}$ & 718 & 0.001 \\
\hline Fortified & $3102^{\mathrm{a}}$ & 519 & $2799^{b * *}$ & 449 & $2875^{\mathrm{b}, \mathrm{c} * \star *}$ & 486 & $2806^{\mathrm{b} * *}$ & 438 & $2929^{\mathrm{c} \star \star}$ & 509 & $<0.0001$ \\
\hline \multicolumn{12}{|c|}{ Transferrin saturation (\%) } \\
\hline Placebo & $19 \cdot 2$ & $7 \cdot 9$ & $19 \cdot 6$ & $10 \cdot 3$ & $17 \cdot 8$ & $9 \cdot 7$ & $19 \cdot 1$ & $9 \cdot 0$ & $17 \cdot 8$ & $11 \cdot 7$ & NS \\
\hline Fortified & $19 \cdot 7$ & $10 \cdot 7$ & $23 \cdot 7$ & $15 \cdot 3$ & $22 \cdot 2^{*}$ & $10 \cdot 8$ & $23 \cdot 4^{*}$ & $9 \cdot 9$ & $23 \cdot 0^{*}$ & $11 \cdot 3$ & NS \\
\hline \multicolumn{12}{|c|}{ Soluble transferrin receptor $(\mathrm{mg} / \mathrm{l})$} \\
\hline Placebo & 1.41 & 0.37 & - & & 1.40 & 0.35 & - & & 1.45 & 0.53 & NS \\
\hline Fortified & $1.48^{\mathrm{a}}$ & 0.60 & - & & $1.33^{\mathrm{b}}$ & 0.46 & - & & $1 \cdot 28^{\mathrm{b} *}$ & 0.43 & 0.001 \\
\hline
\end{tabular}

Mean values were significantly different from the placebo group at each time-point (measured using one-sided tests): ${ }^{\star} P<0.05,{ }^{\star \star} P \leq 0.01,{ }^{\star \star \star} P \leq 0.001$.

$\dagger$ Mean values within a row with unlike superscript letters were significantly different (repeated-measures ANOVA followed by Bonferroni test).

in both groups from baseline, due to juice composition, without significant differences between the $\mathrm{P}$ and $\mathrm{F}$ groups (Table 1).

The intervention induced increases in body weight and BMI, within normal limits (Table 2). Waist circumference did not change during the intervention. Physical activity was unchanged during the study and did not show differences between the groups; it was classified between very light and light (activity factor, $1.68 v .1 .68$ in the $\mathrm{P}$ and $\mathrm{F}$ groups).

Table 3 shows the results of haematological and biochemical markers. Increases in the values of total erythrocytes, haematocrit, mean corpuscular volume, RDW, $\mathrm{Hb}$, serum Fe, serum ferritin and transferrin saturation show recovery from Fe deficiency, while increases in serum transferrin, sTfR and ZnPP denote deterioration, as detailed below.

Total erythrocytes did not show significant differences between the groups. However, the F group showed significantly higher values at week 12 compared with week 4 . Similarly, haematocrit values were significantly higher at week 12 compared with week 4 in this group, and higher haematocrit levels were shown at weeks 12 and 16 in the F group than in the $\mathrm{P}$ group $(P=0 \cdot 01)$. Mean corpuscular volume decreased slightly at week 12 in the $\mathrm{P}$ group, while it tended to increase in the $\mathrm{F}$ group; thus, differences between the groups were significant at week $12(P=0.03)$. RDW was higher in the $\mathrm{F}$ group than in the $\mathrm{P}$ group at weeks 4 and 8 $(P<0.01$ and $0 \cdot 05$, respectively).

$\mathrm{Hb}$ concentrations did not vary in the $\mathrm{P}$ group during the assay (Table 3), but they increased in the $\mathrm{F}$ group and were significantly higher at week 8 compared with baseline, and at weeks 12 and 16 compared with the P group $(P<0.05)$. $\mathrm{ZnPP}$ increased in the $\mathrm{P}$ group and decreased in the $\mathrm{F}$ group during the assay, and the differences between the groups were significant at weeks 8 and $16(P<0.05)$.

No changes in serum Fe concentrations were observed due to either group or time (Table 3). Ferritin concentrations, the principal variable of the present study, significantly increased from week 4 in the $\mathrm{F}$ group, and the values became about $80 \%$ higher compared with the $\mathrm{P}$ group at the end of the assay. In contrast, no changes were observed in the $\mathrm{P}$ group. Serum transferrin fluctuated above $3000 \mathrm{mg} / 1$ in the $\mathrm{P}$ group, while in the $\mathrm{F}$ group, it markedly decreased from week 4 to the end of the assay, and the differences between the groups were significant $(P<0 \cdot 01)$. Accordingly, transferrin saturation was significantly higher from week 8 in the $F$ group with respect to the $\mathrm{P}$ group $(P<0 \cdot 05)$. 
sTfR concentrations significantly decreased in the F group compared with baseline and the $\mathrm{P}$ group (significantly at week 16).

\section{Discussion}

The present study clearly shows that it is feasible to increase Fe status in an at-risk population by daily consumption of a microencapsulated iron pyrophosphate-fortified fruit juice and that the effects are detected in a short period of time ( 4 weeks). This consumption was compatible with the usual diet, and the extra daily $18 \mathrm{mg}$ of Fe provided in each $500 \mathrm{ml}$ juice carton was $100 \%$ of the $\mathrm{RDA}^{(3,4)}$. This quantity of Fe is within the range of supplemental minerals added in European commercial foods ( $20 \%$ of the RDA $/ 100 \mathrm{ml}$ ).

The study fruit juice was fortified with micronised encapsulated iron pyrophosphate coated with lecithin. This form of Fe is dispersible in aqueous solution and has been demonstrated to be highly bioavailable. Its bioavailability is superior to that of non-micronised iron pyrophosphate, which has higher particle size, and to that of non-encapsulated iron pyrophosphate $^{(9-11,29)}$. Roe et al. ${ }^{(30)}$ enriched micronised iron pyrophosphate and ferrous sulphate with different $\mathrm{Fe}$ stable isotopes, and included each Fe form in apple juices to conduct an absorption experiment using the technique of the incorporation of Fe isotopes to erythrocytes. They concluded that the bioavailability of micronised iron pyrophosphate was higher relative to ferrous sulphate, indicating that it could be a useful fortifier for liquid food products.

Several studies using fortified food that supplied amounts of Fe similar to the present study have been reported, generally showing lower efficacy. The consumption of a wheat biscuit enriched with $10 \mathrm{mg}$ of Fe (as encapsulated sulphate) during 22 weeks increased iron ferritin but not $\mathrm{Hb}$ levels in young women ${ }^{(31)}$. A recent study in female soldiers who received $56 \mathrm{mg}$ of $\mathrm{Fe} / \mathrm{d}$ in the form of food bars compared with placebo during 9 weeks has shown no changes in serum ferritin, transferrin saturation, \% RDW and $\operatorname{sTfR}^{(32)}$. The difference between these two studies and ours could be explained by the presence of phytates and the absence of AA in their Fe-fortified products, while the fruit juices of the present study contained no phytate and were fortified with AA. When AA is present, as in one study giving $16 \mathrm{mg}$ of Fe-fortified breakfast cereal with kiwifruit, increases in ferritin and $\mathrm{Hb}$ were observed ${ }^{(33)}$, in agreement with the present study.

In the present study, the food matrix used was an acidic drink that contained AA with a molar AA:Fe ratio of $1 \cdot 7: 1$. Several reports have discussed the importance of this ratio; however, there is no agreement on the optimal ratio to facilitate Fe absorption. A linear relationship between molar AA:Fe ratio and $\mathrm{Fe}$ absorption has been suggested ${ }^{(34)}$, but Cook \& Reddy $^{(15)}$ did not observe differences in $\mathrm{Fe}$ absorption between diets with AA:Fe ratios of 1·2:1, 2.4:1 and 4.5:1. This was attributed to the fact that Fe absorption was measured from a complete diet and not from individual meals. However, their study was criticised by Hunt ${ }^{(35)}$ because subjects were instructed to select or avoid foods according to their AA content, which resulted in highly variable estimates of reported AA intakes. Shah et al. ${ }^{(36)}$ compared Fe absorption in children consuming meals that were accompanied by either apple or orange juice, to which $5 \mathrm{mg}$ of aqueous ferrous sulphate enriched with a stable isotope was added. They found that $\mathrm{Fe}$ absorption was similar to the orange and apple juices, even though the orange juice had much higher vitamin C content.

The effect of the AA:Fe ratio on Fe bioavailability depends on inhibitors present in the food ${ }^{(34)}$, and several authors have suggested a ratio of 2:1 for low-phytate content foods ${ }^{(34,37)}$, which is equivalent to the ratio of the juices assayed in the present study.

It is also important to consider that volunteers in the present study drank the $500 \mathrm{ml}$ of juice separately at least $2 \mathrm{~h}$ after their meals; thus, the provided Fe could not interact with inhibitors present in the diet. Moreover, the low Fe status of these women at the beginning of the assay constituted a factor to favour Fe absorption ${ }^{(13)}$. Therefore, the Fe supplement given in the form of fruit juices was highly bioavailable and was efficacious to improve Fe status in Fe-deficient young women.

The short-term response observed in the present study was unexpected, and the effect was clearly shown in the principal variable, ferritin, a marker of Fe stores. To our knowledge, this is the first study to demonstrate a significant increase in this parameter after the consumption of an Fe-fortified functional beverage during 1 month. Therefore, it was found that in a very short period of time, and using a relatively low additional intake of $\mathrm{Fe}$, the biomarkers of $\mathrm{Fe}$ status improved in nonanaemic Fe-deficient women.

Moreover, it was observed that markers such as $\mathrm{Hb}$ or haematocrit, which were within normal ranges, increased after 3 months. The observed increase in RDW in the enriched group could also indicate a recovery from Fe deficiency. The RDW levels of the $\mathrm{F}$ group became higher in the first months, indicating greater variation in width, and returned to baseline levels at the end of the assay, which corresponds to the average lifespan of erythrocytes ${ }^{(38)}$. These results are consistent with the observed increase in mean corpuscular volume and haematocrit after the consumption of the Feenriched fruit juice.

Other indices, sTfR and ZnPP, which are not widely available as standardised clinical determinations, also indicate an improvement of Fe status. Both reflect marrow Fe status for erythropoiesis and recovery from Fe deficiency ${ }^{(39)}$.

The present study was performed in a European population at risk of Fe-deficiency anaemia (i.e. young menstruating women with low Fe stores), and it is important to indicate that intake of the juice portions was compatible with the usual diet, and that the amount of Fe ingested daily via the enriched juice was one-fifth of the usual therapeutic dose $(100 \mathrm{mg})$ of $\mathrm{Fe}$. Under these experimental conditions, ferritin levels increased by $80 \%$. It should be pointed out that once the assay started, none of the volunteers receiving the Fe-fortified juice dropped out and that they did not complain about digestive discomfort. Therefore, these results are outstanding and suggest that Fe-fortified juices could be used as part of the dietary treatment of anaemic patients in order to correct anaemia more effectively. 
The slight increments of energy intake and body weight indicate high compliance, as all juices contained $10 \mathrm{~g} / 100 \mathrm{ml}$ of carbohydrates (non-added sugars). However, mean bodyweight gain was only $1 \mathrm{~kg}$, and BMI remained within normal limits during the whole intervention. This is a controversial issue because high consumption of fruit juices should be limited in order to prevent obesity, especially in children and young people. However, the present results show that the percentage of energy from protein and fat is reduced by the inclusion of the daily juices in the diet, and the energy profile tended to be more balanced. In this respect, dietary guidelines recommend $45-60 \%$ of energy from carbohydrates, and concerning sugar intake, even added sugar, the European Food Safety Authority has recently indicated that there were insufficient data to set an upper limit ${ }^{(40)}$. Moreover, Western populations show a low consumption of fruits and vegetables $^{(41,42)}$, and the beneficial effects of these fruit juices on other aspects of health should be explored. Nevertheless, sugar content could be reduced in future products that might be used as alternatives in subjects predisposed to anaemia and also obesity or diabetes.

A physiological adaptation appears to occur, since the increase in body weight was observed at the beginning of the assay (data not shown); thus, it is possible that energy from foods other than the juice decreased to compensate for the energy provided by the juices. It should be pointed out that none of the Fe-deficient women participating in this intervention were obese, and that their physical activity was unchanged during the study.

Fe-fortified juice consumption should be recommended to individuals with predisposition to Fe-deficiency anaemia but not to those at risk of excessive Fe intake who do not need to increase their Fe supply, such as patients with Fe over$\operatorname{load}^{(43)}$. Therefore, consumption of an Fe-fortified fruit juice may be considered as a supplement to prevent Fe-deficient anaemia in population risk groups, such as women of childbearing age, pregnant women or children. These groups have a high acceptance of fruit juices, and the concept of functional foods also has high acceptance in developed countries. The present study can have repercussions on public health as prevention of one of the most widespread diseases will have important economic impact, decreasing the need to use public health services and pharmaceutical Fe supplements. The cost benefits of the consumption of this Fe-fortified food compared with those of the pharmaceutical therapy and health care services should be studied. In fact, in the present study, consumption of the Fe-fortified juice led to a recovery from depleted Fe stores (ferritin $<12 \mathrm{ng} / \mathrm{ml}$ ), with only one woman remaining depleted.

Further studies should be focused on the effectiveness of this Fe-fortified beverage in subjects according to their genetic background, in the line of previous studies ${ }^{(43,44)}$. Consumer aspects such as the optimal amount of fruit juice to be drunk, according to concentration of the $\mathrm{Fe}$ salt to be included, cost, palatable aspects and acceptability should also be investigated. Finally, the effect of such Fe-enriched juices on subjects with Fe-deficiency anaemia, obesity, diabetes or CVD and their corresponding nutrigenomic aspects should also be studied.

\section{Acknowledgements}

The present study was supported by Grupo Leche Pascual and Projects reference AGL2006 09519/ALI and reference AGL2009 11437. R. B.-R. was supported by a JAE-predoc grant from European Social Fund and CSIC, Spain, and L. T. was supported by a predoctorate grant from CONACyT, Mexico. The authors are grateful to I. Wright for revising the English text and to the volunteers who participated in the study. The authors' responsibilities were as follows: R. B.-R., A. M. P.-G. and $\mathrm{L}$. T. contributed to the study design, data collection, analysis and manuscript preparation; R. B.-R. and A. M. P.-G. implemented the recruitment and follow-up of study participants; C. G.-V. contributed to the analytical determinations; M. A. D. manufactured the beverages; and M. P. V. was the principal investigator of the study, contributed to the study design and manuscript preparation. M. A. D. works for Grupo Leche Pascual. R. B.-R., A. M. P.-G., L. T., C. G.-V. and M. P. V. had no conflict of interest.

\section{References}

1. World Health Organization (2008) Worldwide prevalence of anaemia 1993-2005. In WHO Global Database on Anaemia [EM de Benoist, I Egli and M Cogswell, editors]. Geneva: World Health Organization.

2. Lynch SR (2005) The impact of iron fortification on nutritional anaemia. Best Pract Res Clin Haematol 18, 333-346.

3. Moreiras O, Carbajal A, Cabrera L, et al. (2009) Ingestas recomendadas de energía y nutrientes para la población española (Recommended intakes of energy and nutrients for the Spanish population). In Tablas de composición de alimentos (Food Composition Tables), 13th ed., pp. 227-230. Madrid: Pirámide, Grupo Anaya, SA.

4. Institute of Medicine and Food and Nutrition Board (2001) Dietary Reference Intakes for Vitamin A, Vitamin K, Arsenic, Boron, Chromium, Copper, Iodine, Iron, Manganese, Molybdenum, Nickel, Silicon, Vanadium, and Zinc. Washington, DC: National Academic Press.

5. Navas-Carretero S, Pérez-Granados AM, Schoppen S, et al. (2009) Iron status biomarkers in iron deficient women consuming oily fish versus red meat diet. $J$ Physiol Biochem 65, 165-174.

6. Hurrell RF (2002) Fortification: overcoming technical and practical barriers. J Nutr 132, 806S-812S.

7. WHO/FAO (2004) Guidelines on Food Fortification with Micronutrients [L Allen, B de Benoist, O Dary and Richard Hurrell, editors]. Geneva: World Health Organization.

8. Navas-Carretero S, Sarria B, Pérez-Granados AM, et al. (2007) A comparative study of iron bioavailability from cocoa supplemented with ferric pyrophosphate or ferrous fumarate in rats. Ann Nutr Metab 51, 204-207.

9. Navas-Carretero S, Pérez-Granados AM, Sarriá B, et al. (2007) Iron bioavailability from pate enriched with encapsulated ferric pyrophosphate or ferrous gluconate in rats. Food Sci Tech Int 13, 159-163.

10. Fidler MC, Walczyk T, Davidsson L, et al. (2004) A micronised, dispersible ferric pyrophosphate with high relative bioavailability in man. BrJ Nutr 91, 107-112. 
11. Moretti D, Zimmermann MB, Wegmuller R, et al. (2006) Iron status and food matrix strongly affect the relative bioavailability of ferric pyrophosphate in humans. Am J Clin Nutr 83, 632-638.

12. Reddy MB, Hurrell RF \& Cook JD (2000) Estimation of nonheme-iron bioavailability from meal composition. Am J Clin Nutr 71, 937-943.

13. Hurrell R \& Egli I (2010) Iron bioavailability and dietary reference values. Am J Clin Nutr 91, 1461S-1467S.

14. Conrad ME \& Schade SG (1968) Ascorbic acid chelates in iron absorption: a role for hydrochloric acid and bile. Gastroenterology 55, 35-45.

15. Cook JD \& Reddy MB (2001) Effect of ascorbic acid intake on nonheme-iron absorption from a complete diet. Am J Clin Nutr 73, 93-98.

16. Nogueira de Almeida C, Crott G, Ricco R, et al. (2002) Control of iron-deficiency anaemia in Brazilian preschool children using iron-fortified orange juice. Nutr Res 23, 27-33.

17. Ash DM, Tatala SR, Frongillo EA Jr, et al. (2003) Randomized efficacy trial of a micronutrient-fortified beverage in primary school children in Tanzania. Am J Clin Nutr 77, 891-898.

18. Abrams SA, Mushi A, Hilmers DC, et al. (2003) A multinutrient-fortified beverage enhances the nutritional status of children in Botswana. J Nutr 133, 1834-1840.

19. Makola D, Ash DM, Tatala SR, et al. (2003) A micronutrientfortified beverage prevents iron deficiency, reduces anemia and improves the hemoglobin concentration of pregnant Tanzanian women. J Nutr 133, 1339-1346.

20. Solon FS, Sarol JN Jr, Bernardo AB, et al. (2003) Effect of a multiple-micronutrient-fortified fruit powder beverage on the nutrition status, physical fitness, and cognitive performance of schoolchildren in the Philippines. Food Nutr Bull 24, S129-S140.

21. Hyder SM, Haseen F, Khan M, et al. (2007) A multiple-micronutrient-fortified beverage affects hemoglobin, iron, and vitamin A status and growth in adolescent girls in rural Bangladesh. J Nutr 137, 2147-2153.

22. Moher D, Schulz KF \& Altman DG (2001) The CONSORT statement: revised recommendations for improving the quality of reports of parallel-group randomized trials. Ann Intern Med 134, 657-662.

23. Koulaouzidis A, Cottier R, Bhat S, et al. (2009) A ferritin level $>50 \mathrm{microg} / \mathrm{L}$ is frequently consistent with iron deficiency. Eur J Intern Med 20, 168-170.

24. de Groot CP, van Staveren WA, Dirren H, et al. (1996) Summary and conclusions of the report on the second data collection period and longitudinal analyses of the SENECA Study. Eur J Clin Nutr 50, Suppl. 2, S123-S124.

25. Navas-Carretero S, Pérez-Granados AM, Schoppen S, et al. (2009) An oily fish diet increases insulin sensitivity compared to a red meat diet in young iron-deficient women. Br J Nutr 102, 546-553.

26. Dietas y cálculos de alimentación (DIAL) (Diets and food calculations), Alce Ingenieria, Spain. http://www. alceingenieria.net/nutricion.htm (accessed December 2009).

27. National Health and Nutrition Examination Survey (NHANES) (2007) Anthropometry procedures manual. http//www.cdc.gov/nchs/data/nhanes/ (accesed September 2008).

28. National Research Council (1989) Recommended Dietary Allowances, 10th ed. Washington, DC: National Academic Press.
29. Navas-Carretero S, Pérez-Granados AM, Sarria B, et al. (2009) Iron absorption from meat pate fortified with ferric pyrophosphate in iron-deficient women. Nutrition 25, 20-24.

30. Roe MA, Collings R, Hoogewerff J, et al. (2009) Relative bioavailability of micronized, dispersible ferric pyrophosphate added to an apple juice drink. Eur J Nutr 48, 115-119.

31. Zimmermann MB, Winichagoon $\mathrm{P}$, Gowachirapant $\mathrm{S}$, et al. (2005) Comparison of the efficacy of wheat-based snacks fortified with ferrous sulfate, electrolytic iron, or hydrogenreduced elemental iron: randomized, double-blind, controlled trial in Thai women. Am J Clin Nutr 82, 1276-1282.

32. Karl JP, Lieberman HR, Cable SJ, et al. (2010) Randomized, double-blind, placebo-controlled trial of an iron-fortified food product in female soldiers during military training: relations between iron status, serum hepcidin, and inflammation. Am J Clin Nutr 92, 93-100.

33. Beck K, Conlon CA, Kruger R, et al. (2011) Gold kiwifruit consumed with an iron-fortified breakfast cereal meal improves iron status in women with low iron stores: a 16-week randomised controlled trial. Br J Nutr $\mathbf{1 0 5}$, 101-109.

34. Lynch SR \& Stoltzfus RJ (2003) Iron and ascorbic acid: proposed fortification levels and recommended iron compounds. J Nutr 133, 2978S-2984S.

35. Hunt JR (2001) How important is dietary iron bioavailability? Am J Clin Nutr 73, 3-4.

36. Shah M, Griffin IJ, Lifschitz CH, et al. (2003) Effect of orange and apple juices on iron absorption in children. Arch Pediatr Adolesc Med 157, 1232-1236.

37. Hurrell RF, Lynch S, Bothwell T, et al. (2004) Enhancing the absorption of fortification iron. A SUSTAIN Task Force report. Int J Vitam Nutr Res 74, 387-401.

38. Dugdale AE (2006) Predicting iron and folate deficiency anaemias from standard blood testing: the mechanism and implications for clinical medicine and public health in developing countries. Theor Biol Med Model 3, 34.

39. Labbe RF \& Dewanji A (2004) Iron assessment tests: transferrin receptor vis-à-vis zinc protoporphyrin. Clin Biochem 37 , 165-174.

40. European Food Safety Authority (EFSA) Panel on Dietetic Products, Nutrition and Allergies (2010) Scientific opinion on dietary reference values for carbohydrates and dietary fibre. EFSA J 8, 1462 (epublication 25 March 2010).

41. Casagrande SS, Wang Y, Anderson C, et al. (2007) Have Americans increased their fruit and vegetable intake? The trends between 1988 and 2002. Am J Prev Med 32, 257-263.

42. Lloyd-Jones DM, Hong Y, Labarthe D, et al. (2010) American Heart Association Strategic Planning Task Force and Statistics Committee. Defining and setting national goals for cardiovascular health promotion and disease reduction: the American Heart Association's strategic Impact Goal through 2020 and beyond. Circulation 121, 586-613.

43. Toxqui L, De Piero A, Courtois V, et al. (2010) Iron deficiency and overload. Implications in oxidative stress and cardiovascular health. Nutr Hosp 25, 350-365.

44. Sarriá B, López-Parra AM, Navas-Carretero S, et al. (2007) Hepcidin, transferrin (exon 7) and hemochromatosis genotyping suggests that haplotype block analysis is the best strategy for predicting iron deficiency phenotype in women. Nutr Res 27, 672-678. 